\title{
PENILAIAN TINGKAT KESEHATAN BANK SYARIAH MANDIRI: PENDEKATAN METODE RGEC (RISK PROFILE, GOOD CORPORATE GOVERNANCE, EARNING DAN CAPITAL)
}

\author{
Muhammad Rizky Husain ${ }^{1}$, Nor Hikmah², Chairina ${ }^{3}$ \\ 1,2 3 Universitas Lambung Mangkurat \\ $\triangle$ chairina.adnan@yahoo.co.id
}

\begin{abstract}
The purpose of this study is to analyze the health level of Bank Syariah Mandiri in the period 2012-2016 with RGEC method. This method consists of four factors. These factors are risk profile, good corporate governanc),earning and capital. This research is a descriptive study. Data analysis unit of this research is Annual Report of Bank Syariah Mandiri in the period of 2012 until 2016, this research use quantitative data with source of secondary data and analysis method of data in this research is descriptive quantitative. The results of research show that the performance decline of Bank Syariah Mandiri in 2013 is caused by increased operating expenses exceeding the increase in operating income. The performance decline of Bank Syariah Mandiri in 2014 is caused by losses suffered by Bank Syariah Mandiri resulting from a decrease in operating income accompanied by an increase in operating expenses while the total of assets increased. However, in 2015, the level of health of BSM settled in rank 3 with the title of being quite healthy, and the level of health of BSM in 2016 increased to rank 2 with a healthy predicate.
\end{abstract}

Keywords $\quad$ : health level of bank; performance; expense; RGEC; BSM.

\section{LATAR BELAKANG}

Saat ini industri perbankan di Indonesia telah berkembang pesat dengan tumbuhnya bank-bank syariah yang menawarkan investasi dan produk keuangan yang berbeda dengan bank konvensional. Bank syariah merupakan bank yang dalam operasinya menerapkan syariah Islam. Bank syariah merupakan sebuah lembaga ekonomi yang beroperasi dengan berlandaskan prinsip-prinsip syariah, dimana bank syariah telah menarik banyak bank konvensional yang kemudian membuka kantor-kantor cabang bank syariah.

Salah satu bank syariah dengan jaringan terbesar di Indonesia, yaitu Bank Syariah Mandiri atau dikenal dengan BSM. Didirikan di Indonesia pada tahun 1999, Bank Syariah Mandiri adalah bank syariah yang memiliki jumlah aset tertinggi di Indonesia, yaitu Rp 78,8 triliun per 31 Desember 2016, jumlah jaringan kantor dan ATM mencapai 765 kantor dan 206 ribu unit ATM tersebar di seluruh Indonesia yang melayani nasabah dengan jumlah mencapai lebih dari 6,8 juta rekening. Sebagai salah satu bank syariah dengan jaringan kantor terbanyak di Indonesia, Bank Syariah Mandiri harus di nilai tingkat kesehatannya untuk menjaga kelancaran dalam 
pelayanan nasabahnya. Undang-Undang No. 21 Tahun 2008 Tentang Perbankan Syariah menjelaskan bahwa bank syariah dan unit usaha syairah diwajibkan untuk memelihara tingkat kesehatannya. Kemudian bank juga harus terus meningkatkan kesehatannya sehingga kepercayaan di masyarakat kepada bank meningkat.

Kesehatan bank mencerminkan kinerja dan kondisi bank secara umum yang digunakan untuk memutuskan strategi dan menjalankan pengawasan bank. Selain itu, kesehatan bank merupakan kepentingan seluruh pihak, yaitu pemilik, pengelola, investor dan nasabah untuk mengevaluasi kinerja bank dalam menerapkan prinsip kehati-hatian. (POJK No. 8/POJK.03/2014). Menurut SE BI nomor. 13/24/DPNP, 25 oktober 2011, tingkat kesehatan perbankan syariah dipengaruhi oleh berbagai faktor, antara lain adalah profil risiko bank, jumlah pembiayaan yang bermasalah, likuiditas, tata kelola perusahaan, faktor permodalan dan faktor rentabilitas.

Berdasarkan SE BI nomor. 13/24/DPNP, 25 oktober 2011, rentabilitas (earning) merupakan kemampuan bank menghasilkan laba dari investasi modal dalam aktiva keseluruhan yang ditunjukan dengan indikator rasio ROA, dan tingkat efisiensi usaha serta kemampuan bank dalam memanajemen biaya operasional, ditunjukan dengan indikator rasio BOPO. Menurut Laporan Tahunan BSM, Rasio ROA pada BSM periode tahun 2012 sampai 2016, secara berturut turut adalah 2,25\%, 1,53\%, 0,04\%, 0,56\% dan $0,59 \%$.

\section{TEORI DAN METODE}

\subsection{Penilaian Kesehatan Bank}

Berdasarkan Laporan Tahunan BSM, terdapat penurunan rasio ROA dari tahun 2012 sampai tahun 2014, menunjukan penurunan penghasilan laba oleh bank terhadap investasi dalam aktiva keseluruhan, di tahun 2014, BSM memperoleh rasio ROA 0,04\%, sedangkan menurut Surat Edaran Bank Indonesia Nomor 13/24/DPNP, 2011 tingkat rasio ROA tersebut termasuk dalam kategori tidak memadai dengan kriteria bank yang mendapat kerugian besar dengan rasio ROA dibawah 0. Rasio BOPO Bank Syariah Mandiri pada periode tahun 2012 sampai 2016 adalah 73\%, 86,46\%, 100,60\%, $94,78 \%$ dan $94,12 \%$.

Berdasarkan Laporan Tahunan publikasi BSM, terdapat kenaikan rasio BOPO dari tahun 2012 sampai tahun 2014 yang menunjukan penurunan tingkat efisiensi usaha bank. Pada tahun 2014, 2015 dan 2016. Bank Syariah Mandiri memiliki rasio BOPO secara berturut-turut sebagai berikut: 100,60\%, 94,78\% dan 94,12\%, Sedangkan menurut Surat Edaran Bank Indonesia Nomor 13/24/DPNP, 2011 tingkat rasio BOPO tersebut termasuk dalam kategori tidak memadai dengan kriteria tingkat efisiensi yang sangat buruk dengan rasio BOPO lebih dari 89\%. Sehingga dari pemaparan dua rasio keuangan tersebut dapat disimpulkan bahwa Bank Syariah Mandiri mengalami permasalahan rentabilitas dan membutuhkan suatu analisis untuk mengetahui kondisinya dalam jangka waktu tertentu, yaitu analisis tingkat kesehatan bank. 
Sebelumnya ksehatan bank dapat dinilai metode CAMELS yang di tetapkan oleh Bank Indonesia dalam Peraturan Bank Indonesia No. 6/10/PBI/2004. Kemudian bank Indonesia menyempurnakan metode penilaian kesehatan bank menjadi metode RGEC yang terdiri dari faktor Risk profile, faktor GCG, faktor Earning, dan faktor Capital yang diumumkan dalam SE BI nomor. 13/24/DPNP 25 oktober 2011. Dengan diterapkannya RGEC oleh Bank Indonesia, diharapkan bank dapat lebih dini megindetifikasi masalah dan menindaklanjutinya lebih cepat, kemudian menerapkan Good Corporate Governance dan risk management yang lebih baik sehingga bank dalam menghadapi masalah.

Dari pemaparan tersebut, maka kesehatan bank sangat penting untuk di nilai sebagai upaya meningkatkan kinerja bank syariah. Bank Syariah Mandiri wajib untuk dinilai tingkat kesehatannya untuk terus menjaga kualitas kinerjanya Dimana tingkat kesehatan bank mencerminkan kinerja dan kondisi secara umum bank (tidak sehat, kurang sehat, cukup sehat, sehat, atau sangat sehat) melalui faktor-faktor dalam metode RGEC.

\subsection{Metode Penelitian}

Penelitian ini berupa studi deskriptif kuantitstif untuk menganalisis kesehatan Bank Syariah Mandiri periode tahun 2012 sampai tahun 2016 dengan objek yang diteliti adalah tingkat kesehatan Bank Syariah Mandiri yang dinilai menggunakan RGEC. Penelitian dilakukan di Bank Syariah Mandiri dengan mengakses website resmi bank. Unit (satuan) analisis data penelitian Laporan Tahunan Bank Syariah Mandiri periode tahun 2012 hingga 2016. Teknik analisis data penelitian dilakukan scara deskrptif kuantitatif, yaitu dengan cara melakukan analisis dan membandingkan teori dengan praktek peniliaian kesehatan bank, dimana perhitungan masing-masing rasio keuangan yang diteliti pada peringkat kompositnya. Hasil perhitungan tersebut selanjutnya digunakan sebagai indikator pengukuran tingkat kesehatan Bank Syariah Mandiri.

\section{Tabel 1}

\section{Pengukuran GRECH}

\begin{tabular}{lll}
\hline No & Indikator & Pengukuran \\
\hline 1 & Risk profile: & 1 (low), \\
& $\begin{array}{l}\text { Risiko kredit, risiko pasar, risiko likuiditas, } \\
\text { risiko operasional, risiko hukum, risiko stratejik, }\end{array}$ & peringkat 2 (low to moderate), \\
& $\begin{array}{l}\text { risiko kepatuhan, risiko reputasi, risiko imbal } \\
\text { hasil, dan risiko investasi }\end{array}$ & peringkat 4 (moderate to high), \\
& & dan peringkat 5 (high). \\
\hline 2 & $\begin{array}{l}\text { Good Corpotrate Governance (GCG) bersifat self- } \\
\text { assestment : }\end{array}$ & $\mathrm{NK}<1,5 \quad$ = Sangat baik \\
& & $1,5<\mathrm{NK}<2,5 \quad=$ Baik \\
\hline
\end{tabular}



Pelaksanaan tugas dan tanggung jawab Dewan
Komisaris, Pelaksanaan tugas dan tanggung jawab Direksi, Kelengkapan dan pelaksanaan tugas Komite, Pelaksanaan tugas dan tanggung

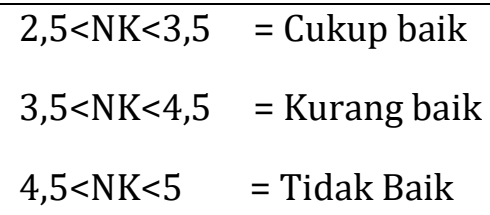
jawab Dewan Pengawas Syariah, Pelaksanaan prinsip syariah dalam kegiatan penghimpunan dana dan penyaluran dana serta pelayanan jasa, Penanganan benturan kepentingan, Penerapan fungsi kepatuhan, Penerapan fungsi audit intern, Penerapan fungsi audit ekstern, Batas Maksimum Penyaluran Dana (BMPD), dan Transparansi kondisi keuangan dan non keuangan BUS, laporan pelaksanaan Good Corporate Governance serta pelaporan internal.

\section{$3 \quad$ Earning}

- ROA (Return on Assets)

$$
\begin{aligned}
\text { ROA }= & \frac{\text { Laba Sebelum Pajak }}{\text { Rata- } \text { Rata Total Aset }}
\end{aligned}
$$

- BOPO(Biaya Operasional Terhdap Pendapatan Operasional)

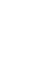


Tentang Penilaian Tingkat Kesehatan Bank Umum Syariah dan Unit Usaha Syariah terdiri atas 10 (sepuluh) dengan tambahan penilaian, risiko imbal hasil, dan risiko investasi. Berikut adalah rangkuman profil risiko Bank Syariah Mandiri selama tahun 2012-2016.

\section{Tabel 2}

Matriks Penilaian Faktor Profil Risiko

\begin{tabular}{|c|c|c|c|c|c|}
\hline \multirow[t]{2}{*}{ Jenis Risiko } & \multicolumn{5}{|c|}{ Tingkat Risiko } \\
\hline & 2012 & 2013 & 2014 & 2015 & 2016 \\
\hline $\begin{array}{l}\text { Risiko } \\
\text { Kredit }\end{array}$ & 2 & 3 & 4 & 3 & 2 \\
\hline $\begin{array}{l}\text { Risiko } \\
\text { Pasar }\end{array}$ & 1 & 1 & 2 & 2 & 1 \\
\hline $\begin{array}{l}\text { Risiko } \\
\text { Likuiditas }\end{array}$ & 2 & 2 & 2 & 2 & 1 \\
\hline $\begin{array}{l}\text { Risiko } \\
\text { Operasional }\end{array}$ & 3 & 3 & 4 & 3 & 3 \\
\hline $\begin{array}{l}\text { Risiko } \\
\text { Hukum }\end{array}$ & 3 & 4 & 2 & 2 & 2 \\
\hline $\begin{array}{l}\text { Risiko } \\
\text { Stratejik }\end{array}$ & 2 & 2 & 2 & 2 & 2 \\
\hline $\begin{array}{l}\text { Risiko } \\
\text { Kepatuhan }\end{array}$ & 1 & 1 & 2 & 3 & 2 \\
\hline $\begin{array}{l}\text { Risiko } \\
\text { Reputasi }\end{array}$ & 2 & 2 & 2 & 2 & 1 \\
\hline $\begin{array}{l}\text { Risiko } \\
\text { Imbal Hasil }\end{array}$ & - & - & 2 & 2 & 2 \\
\hline $\begin{array}{l}\text { Risiko } \\
\text { Investasi }\end{array}$ & - & - & 3 & 2 & 2 \\
\hline $\begin{array}{l}\text { Peringkat } \\
\text { Komposit }\end{array}$ & 2 & 2 & 2 & 2 & 2 \\
\hline
\end{tabular}

Sumber: Laporan Tahunan Bank Syariah Mandiri 


\section{Good Corporate Governance}

Penilaian terhadap faktor good corporate governance dilakukan secara selfassessment, di mana Bank Syariah Mandiri menilai sendiri komponen GCG-nya. Berdasarkan Laporan Tahunan Bank Syariah Mandiri. Nilai komposit dan predikat good corporate governance pada Bank Syariah Mandiri periode tahun 2012 sampai 2016 adalah sebagai berikut:

\section{Tabel 3}

Nilai Komposit dan Predikat Faktor Good Corporate Governance

\begin{tabular}{ccc}
\hline Periode & $\begin{array}{c}\text { Nilai } \\
\text { Komposit }\end{array}$ & Predikat \\
\hline 2012 & 2 & Baik \\
\hline 2013 & 2 & Baik \\
\hline 2014 & 2 & Baik \\
\hline 2015 & 2 & Baik \\
\hline 2016 & 1 & Sangat Baik \\
\hline
\end{tabular}

Sumber: Laporan Tahunan Bank Syariah Mandiri

Berdasarkan hasil self-assestment yang dilakukan Bank Syariah Mandiri terhadap faktor good corpotrate governance, Bank Syariah Mandiri mendapatkan peringkat 2 pada tahun 2012 sampai tahun 2015, dan mengalami peningkatan pada tahun 2016 menjadi peringkat 1 dengan predikat sangat baik. Peringkat tersebut menunjukan BSM telah melakukan penerapan atas prinsip good corpotrate governance yang sebagaimana diatur oleh Otoritas Jasa Keuangan dan Bank Indonesia dengan baik.

\section{Earning}

Earning atau penilaian rentabilitas mengukur kinerja bank dalam menghasilkan laba dan kemampuan manajemen bank dalam mengendalikan biaya operasional. Perbandingan biaya operasional dengan pendapatan operasional digunakan untuk menilai tingkat efisiensi bank dalam melakukan kegiatan operasi. Pengukuran tingkat rentabilitas menggunakan indikator rasio ROA (Return on Assets) dan rasio BOPO (Biaya Operasional Terhadap Pendapatan Operasional).

Tabel 4

Rasio ROA dan Rasio BOPO

\begin{tabular}{ccc}
\hline Periode & ROA & BOPO \\
\hline 2012 & $2,25 \%$ & $73,00 \%$ \\
\hline 2013 & $1,53 \%$ & $86,46 \%$ \\
\hline 2014 & $-0,04 \%$ & $100,60 \%$ \\
\hline 2015 & $0,56 \%$ & $94,78 \%$ \\
\hline 2016 & $0,59 \%$ & $94,12 \%$ \\
\hline
\end{tabular}

Sumber: Laporan Tahunan Bank Syariah Mandiri 
BSM padatahun 2013 memperoleh peningkatan nilai BOPO sebesar 13,46\% dan menjadikan komponen faktor rentabilitas rasio BOPO menurun dari peringkat 1 menjadi peringkat 3 dengan predikat cukup memadai, penurunan peringkat rasio BOPO ini menyebabkan tingkat kesehatan Bank Syariah Mandiri pada tahun 2013 menurun dari peringkat 1 menjadi peringkat 2 .

Pada tahun 2014, BSM mengalami penurunan nilai rasio ROA sebesar 1,57\% sehingga menurunkan komponen rentabilitas ROA dari peringkat 1 menjadi peringkat 5 dengan predikat tidak memadai dan penurunan tingkat efisiensi usaha yang ditunjukan dengan nilai rasio BOPO yang meningkat sebesar 14,14\% dan menjadikan peringkat komponen rentabilitas rasio BOPO menurun dari peringkat 1 menjadi peringkat 5 dengan predikat tidak memadai sehingga menyebabkan penurunan tingkat kesehatan Bank Syariah Mandiri menjadi peringkat 3.

\section{Capital}

Capital atau faktor permodalan dinilai berdasarkan indikator kecukupan modal bank untuk mengantisipasi potensi kerugian dari profil risiko yang disertai dengan pengelolaan permodalan yang baik, sesuai dengan karakteristik, skala usaha dan kompleksitas usaha bank. Permodalan yang dinilai, diukur berdasarkan rasio CAR (Capital Adequacy Ratio) yang telah ditetapkan oleh Bank Indonesia. Rasio CAR adalah perbandingan modal terhadap aktiva tertimbang menurut risiko (ATMR). Berikut Rasio CAR (Capital Adequacy Ratio) pada Bank Syariah Mandiri periode tahun 2012-2016 adalah sebagai berikut:

Tabel 5

\section{Rasio Capital Adequacy Ratio (CAR)}

\begin{tabular}{lccc}
\hline Periode & CAR & Peringkat & Predikat \\
\hline 2012 & $13,82 \%$ & 1 & Sangat Memadai \\
\hline 2013 & $14,10 \%$ & 1 & Sangat Memadai \\
\hline 2014 & $14,12 \%$ & 1 & Sangat Memadai \\
\hline 2015 & $12,85 \%$ & 1 & Sangat Memadai \\
\hline 2016 & $14,10 \%$ & 1 & Sangat Memadai \\
\hline
\end{tabular}

Sumber: Laporan Tahunan Bank Syariah Mandiri

Berdasarkan penilaian pada faktor permodalan, diketahui Bank Syariah Mandiri mendapatkan peringkat 1 pada tahun 2012 sampai tahun 2016, peringkat ini menunjukan Bank Syariah Mandiri telah memenuhi kecukupan permodalan minimum bank dalam mengantisipasi munculnya kerugian dari riskprofile dan mengelola permodalan dengan baik. 
Tabel 6

Ringkasan Peringkat Komposit Tingkat Kesehatan

\begin{tabular}{|c|c|c|c|}
\hline Faktor & Komponen & Peringkat & Predikat \\
\hline Risk Profile & Komposit & 2 & Memadai \\
\hline GCG & Komposit & 2 & Baik \\
\hline \multirow[t]{2}{*}{ Earning } & ROA & 1 & Sangat Memadai \\
\hline & BOPO & 1 & Sangat Memadai \\
\hline Capital & CAR & 1 & Sangat Memadai \\
\hline \multicolumn{2}{|c|}{ Komposit Tahun 2012} & 1 & Sangat Sehat \\
\hline Faktor & Komponen & Peringkat & Predikat \\
\hline Risk Profile & Komposit & 2 & Memadai \\
\hline$G C G$ & Komposit & 2 & Baik \\
\hline \multirow[t]{2}{*}{ Earning } & ROA & 1 & Sangat Memadai \\
\hline & BOPO & 3 & Cukup Memadai \\
\hline Capital & CAR & 1 & Sangat Memadai \\
\hline \multicolumn{2}{|c|}{ Komposit Tahun 2013} & 2 & Sehat \\
\hline Faktor & Komponen & Peringkat & Predikat \\
\hline Risk Profile & Komposit & 2 & Memadai \\
\hline GCG & Komposit & 2 & Baik \\
\hline \multirow[t]{2}{*}{ Earning } & ROA & 5 & Tidak Memadai \\
\hline & BOPO & 5 & Tidak Memadai \\
\hline Capital & CAR & 1 & Sangat Memadai \\
\hline \multicolumn{2}{|c|}{ Komposit Tahun 2014} & 3 & Cukup Sehat \\
\hline Faktor & Komponen & Peringkat & Predikat \\
\hline Risk Profile & Komposit & 2 & Memadai \\
\hline$G C G$ & Komposit & 2 & Baik \\
\hline \multirow[t]{2}{*}{ Earning } & ROA & 3 & Cukup Memadai \\
\hline & BOPO & 5 & Tidak Memadai \\
\hline Capital & CAR & 1 & Sangat Memadai \\
\hline \multicolumn{2}{|c|}{ Komposit Tahun 2015} & 3 & Cukup sehat \\
\hline Faktor & Komponen & Peringkat & Predikat \\
\hline Risk Profile & Komposit & 2 & Memadai \\
\hline$G C G$ & Komposit & 1 & Baik \\
\hline \multirow[t]{2}{*}{ Earning } & ROA & 3 & Cukup Memadai \\
\hline & BOPO & 5 & Tidak Memadai \\
\hline Capital & CAR & 1 & Sangat Memadai \\
\hline \multicolumn{2}{|c|}{ Komposit Tahun 2016} & 2 & Sehat \\
\hline
\end{tabular}

Sumber: Data diolah kembali

Berdasarkan penilaian pada faktor-faktor RGEC, diketahui faktor riskprofile BSM pada periode 2012 hingga periode 2016 mendapatkan peringkat komposit 2 dengan predikat memadai. Hal ini menunjukan Bank Syariah Mandiri telah mampu 
mengendalikan tingkat risiko inheren dengan baik dan menerapkan manajemen risiko bank sesuai dengan ketentuan Otoritas Jasa Keuangan dan Bank Indonesia dengan efektif. Dari peringkat komposit tersebut, maka diperoleh tingkat kesehatan BSM periode tahun 2012-2016, yaitu sebagai berikut.

Tabel 7

Tingkat Kesehatan BSM Periode Tahun 2012-2016

\begin{tabular}{ccc}
\hline Tahun & Peringkat & Predikat \\
\hline 2012 & 1 & Sangat Sehat \\
\hline 2013 & 2 & Sehat \\
\hline 2014 & 3 & Cukup Sehat \\
\hline 2015 & 3 & Cukup Sehat \\
\hline 2016 & 2 & Sehat
\end{tabular}

Sumber: Data diolah kembali

Berdasarkan hasil studi diatas, tingkat kesehatan BSM di tahun 2012 mendapatkan pringkat 1 dengan predikat sangat sehat. Di tahun 2013, tingkat kesehatan BSM menurun menjadi peringkat 2 dengan predikat sehat. Tingkat kesehatan BSM di tahun 2014 menurun menjadi peringkat 3 dengan predikat cukup sehat. kemudian di tahun 2015, tingkat kesehatan BSM menetap di peringkat 3 dengan predikat cukup sehat, tingkat kesehatan BSM di tahun 2016 meningkat menjadi peringkat 2 dengan predikat sehat.

\section{IMPLIKASI HASIL PENELITIAN}

Hasil penelitian ini diharapkan dapat berkontribusi Bank Syariah Mandiri untuk meningkatkan kepercayaan nasabah, masyarakat dan calon investor kepada bank, maka Bank Syariah Mandiri harus mampu meningkatkan kinerja bank, penelitian ini menunjukan penurunan faktor earning pada komponen rasio ROA dan BOPO berdampak pada penurunan tingkat kesehatan bank dan peningkatan pada faktor good corporate governance berdampak pada peningkatan kesehatan bank. Diharapkan Bank Syariah Mandiri dapat menjaga tingkat kesehatan banknya dengan meningkatkan perolehan laba, mengoptimalkan pendapatan operasional dan melakukan pengendalian biaya operasional, serta mempertahankan tata kelola perusahaan yang baik. 


\section{PENUTUP}

\section{Kesimpulan}

Berdasarkan hasil penelitian, dapat disimpulkan bahwa penurunan faktor earning pada komponen rasio BOPO pada tahun 2013 menyebabkan tingkat kesehatan Bank Syariah Mandiri mengalami penurunan menjadi peringkat 2, kemudian pada tahun 2014 terdapat penurunan rasio ROA dan penurunan rasio BOPO yang menyebabkan tingkat kesehatan Bank Syariah Mandiri menurun menjadi peringkat 3.

Penurunan rasio ROA memperlihatkan bahwa di tahun 2014 produktivitas aset dalam menghasilkan laba menurun, dan semakin besar persentase rasio BOPO pada tahun 2013 dan 2014 menunjukan menurunnya kemampuan bank dalam hal manajemen biaya operasional. Sesuai dengan penetapan penilaian rasio ROA dan rasio BOPO berdasarkan Surat Edaran Bank Indonesia, pada tahun 2014 Bank Syariah Mandiri memiliki rasio ROA negatif dan rasio BOPO yang menunjukan tingkat efisiensi sangat buruk (rasio BOPO >89\%), sehingga untuk meningkatkan kinerja rasio tersebut, maka diharapkan bank dapat meningkatkan perolehan laba, menjaga tingkat efisiensi bank dengan melakukan pengendalian biaya operasional serta mengoptimallkan pendapatan operasional.

Saran

Bank Syariah Mandiri perlu meningkatkan faktor earning dan menjaga tingkat efisiensi bank agar dapat mempertahankan kinerja bank. Untuk meningkatkan kinerja rentabilitas dapat dilakukan dengan cara meningkatkan perolehan laba, yaitu dengan meningkatkan pendapatan operasional dari piutang dan pendapatan dari bagi hasil mudharabah yang menurun pada tahun 2014. Untuk menjaga tingkat efisiensi usaha, bank dapat melakukan pengendalian beban operasional dengan menerapkan program green office secara menyeluruh untuk melakukan berbagai penghematan, serta mengefisiensikan ekspansi jaringan dan penambahan pegawai agar tidak memberatkan beban kepegawaian bank yang meningkat pada tahun 2013 dan tahun 2014. Untuk peneliti selanjutnya dimasa yang akan datang, disarankan agar memperluas serta mengembangkan ruang lingkup penelitian mengenai kesehatan bank dengan indikator-indikator lain dalam mengukur tingkat kesehatan bank. 


\section{DAFTAR PUSTAKA}

Bank Indonesia. (2004, April 12). Peraturan Bank Indonesia nomor: 6/10/PBI/2004 tentang penilaian tingkat kesehatan bank umum. Peraturan Bank Indonesia. Jakarta: Bank Indonesia.

Bank Indonesia. (2004, Mei 31). Surat Edaran Bank Indonesia nomor: 6/23/DPNP perihal: sistem penilaian kesehatan bank umum. Surat Edaran Bank Indonesia. Jakarta: Bank Indonesia.

Bank Indonesia. (2010, April 30), Surat Edaran Bank Indonesia nomor 12/13/DPbS Perihal Pelaksanaan Good Corporate Governance Bagi Bank Syariah dan Unit Usaha Syariah. Surat Edaran Bank Indonesia. Jakarta: Bank Indonesia

Bank Indonesia. (2011, Januari 5). Peraturan Bank Indonesia nomor: 13/PBI/2011 tentang tata cara penilaian kesehatan bank umum. Peraturan Bank Indonesia. Jakarta: Bank Indonesia.

Bank Indonesia. (2011, Januari 25). Surat Edaran Bank Indonesia nomor 13/24/DPNP Perihal: penilaian bank umum konvensional di Indonesia . Surat Edaran Bank Indonesia. Jakarta: Bank Indonesia.

Bank Indonesia. (2013, April 29). Surat Edaran Bank Indonesia nomor 15/15/DPNP perihal: Pelaksanaan Good Corporate Governance Bagi Bank Umum. Peraturan Bank Indonesia. Jakarta: Bank Indonesia.

Paramartha, I. M., \& Darmayanti, P. A. (2017). Penilaian tingkat kesehatan bank dengan metode RGEC pada PT. Bank Mandiri (Persero), Tbk. E-Jurnal Manajemen Unud, 6(2), 948-974.

Otoritas Jasa Keuangan. (2014). Peraturan otoritas jasa keuangan nomor 8/POJK.03/2014 tentang penilaian tingkat kesehatan bank umum syariah dan unit usaha syariah. Peraturan Otoritas Jasa Keuangan. Otoritas Jasa Keuangan.

Otoritas Jasa Keuangan. (2014). Surat edaran otoritas jasa keuangan nomor 10/SEOJK.03/2014 tentang penilaian tingkat kesehatan bank umum syariah dan unit usaha syariah. Surat Edaran Otoritas Jasa Keuangan. Jakarta: Otoritas Jasa Keuangan.

Otoritas Jasa Keuangan. (2017, November 14). Statistik perbankan syariah September 2017. Retrieved from Otoritas Jasa Keuangan: diakses tanggal 10 Oktober 2017.

Rivai, V., \& Veithzal, A. P. (2008). Islamic Financial Management. Jakarta: PT Raja Grafindo Persada. 
Undang-Undang Republik Indonesia No 21 tahun 2008 tentang perbankan syariah. (2008, Juli 16). Undang-Undang. Jakarta. 